\title{
Mortars with phase change materials - Part II: Durability evaluation
}

\author{
CUNHA Sandra ${ }^{1, a}$, AGUIAR Josée,b, FERREIRA Victor ${ }^{2, c}$, TADEU António $^{3, \mathrm{~d}}$ \\ and GARBACZ Andrzej, \\ ${ }^{1}$ University of Minho, Campus de Azurém, 4800-058 Guimarães, Portugal \\ ${ }^{2}$ University of Aveiro, Campus Universitário de Santiago, 3810-193 Aveiro, Portugal \\ ${ }^{3}$ University of Coimbra, Rua Luís Reis Santos - Pólo II da Universidade, 3030-788 Coimbra, \\ Portugal \\ ${ }^{3}$ Warsaw University of Technology, PI. Politechniki 1, 00-661 Warszawa, Poland \\ a'sandracunha86@gmail.com, ’aguiar@civil.uminho.pt, 'victorf@ua.pt, ${ }^{d}$ tadeu@dec.uc.pt, \\ a.garbacz@il.pw.edu.pl
}

Keywords: Durability, Mortars, Phase Change Materials, Freeze-thaw resistance and water absorption.

\begin{abstract}
The industry of construction is responsible for the high consumption of raw materials, energy and waste production. As such, it becomes imperative to develop and study new constructive solutions with greater sustainable value. The mortars with incorporation of phase change materials (PCM) have the ability to regulate the temperature inside buildings, contributing to the thermal comfort and reducing the use of heating and cooling equipment, using only the energy supplied by the sun. However, the incorporation of phase change materials in mortars modifies its characteristics. The main focus of this study was the durability of mortars with PCM incorporation based in different binders. The binders studied were aerial lime, hydraulic lime, gypsum and cement. For each type of binder, different mortars were developed with different content of PCM. The proportion of PCM studied was $0 \%$ and $40 \%$ of the mass of the sand. It was possible to observe that the incorporation of PCM in mortars caused differences in properties such as water absorption by capillarity, water absorption by immersion and degradation after freeze-thaw cycles.
\end{abstract}

\section{Introduction}

In a society increasingly concerned about sustainability and good construction practices it becomes urgent to develop and study new and durable constructive solutions.

The durability of materials is not an intrinsic characteristic, but rather a characteristic related to material performance throughout their life, which itself is subject to some environmental conditions. Thus, it is not possible to generalize the concept of durability, since it must be specified taking into account the environment where the material will be applied [1].

The durability of construction materials is directly related to their sustainability. The most durable materials lead to minor rehabilitation actions, which consequently results in lower consumption of raw materials, energy and waste production. This characteristic of mortars is closely linked to the characteristics of binders and aggregates, the ratio binder/aggregate, content of water, water absorption by capillarity, presence of additives and curing conditions [2].

The scientific community has conducted studies in the framework of the durability of materials. However, the study of the durability of mortars incorporating phase change materials is one of the main knowledge gaps. Therefore, the main objective of this work was the study of the durability of mortars with PCM incorporation based on different binders. Tests were performed in 12 different compositions, evaluating the absorption of water by capillarity, water absorption by immersion and the behaviour during freeze-thaw cycles. 


\section{Phase Change Materials}

Phase change materials possess the capability to alter its own state as function of the environmental temperature [3]. In other words, when the surrounding environmental temperature of PCM increases until the materials fusion point, it suffers a change from a solid state to a liquid state, absorbing and storing the heat energy from the environment. On the other hand when the temperature decreases until the PCM solidification point, the material alters from the liquid state to solid state, releasing the previously stored energy to the environment. This application could be made in coating mortars of buildings, with advantage in the passive regulation of internal temperature with increase of thermal inertia [4].

The PCM must be encapsulated for its correct use, otherwise during the liquid phase there is a possibility that it moves from the original area of application. There are two main forms of encapsulation, macroencapsulation and microencapsulation. The macroencapsulation is based in the introduction of PCM into tubes, panels or other large containers. It is usually carried out in containers with more than $1 \mathrm{~cm}$ of diameter and presents a better compatibility with the material, improving the handling in construction [5]. The microencapsulation of phase change material consists on covering the material particles, with a material, usually a polymer, commonly known capsule, with dimensions between $1 \mu \mathrm{m}$ to $60 \mu \mathrm{m}$. The polymer used could be polymethylmethacrylate, polyuria or polyurethane and should respond at some demands of operation, as high heat transfer. The microcapsules can be spherical or asymmetric and with variable shape. The advantage of this encapsulation process is the improvement of heat transfer, through its large surface area $[5,6]$.

In 1983 emerged the first classification of substances used for thermal storage. These are classified as organic, inorganic and eutectic mixtures. Organic materials can be non-paraffinic or paraffinic. Usually, they have congruent phase changes without degradation. The inorganic materials are classified as hydrated salts and metals. The eutectic mixtures result from the combination of two or more compounds of organic and/or inorganic nature. As such, it is possible to correspond to the need of more suitable transition temperatures for the demands $[5,7]$.

The incorporation of PCM microcapsules in mortars brings social, economic and environmental benefits, demonstrating a significant contribution to a construction with a higher value of sustainability. The social benefits derive from the thermal comfort increase inside buildings, given that nowadays this is an important requirement and frequently demanded by buyers and potential sellers as an important decision parameter. The increase of thermal comfort is achieved by the thermal capacity of the PCM, allowing store and release of energy, keeping the interior temperature sensibly constant, or at least with less variation. The environmental aspect concerns the fossil fuels depletion, given that this technology aims at maintaining constant temperatures inside the building, consequently leading to a decrease on air conditioning equipment usage. The economic benefit is related to the technology adequacy and implementation costs. These should be supported and easily amortized by the user. It may also be noted that the economic benefits of reduced energy consumption and lag times for lower demand, are evident and can be achieved with the use of PCM.

\section{Materials, compositions and fabrication}

Materials. The selection of the materials took into account previous work [8-10]. The influence of adding PCM in mortars for interior coating were studied. Mortars were developed based on the following binders: aerial lime, hydraulic lime, gypsum and cement. The used aerial lime featured a purity of $90 \%$ and density of $2450 \mathrm{~kg} / \mathrm{m}^{3}$. The gypsum corresponds to a traditional one, with high fineness and density of $2740 \mathrm{~kg} / \mathrm{m}^{3}$. The hydraulic lime was a natural lime (NHL5) with density of $2550 \mathrm{~kg} / \mathrm{m}^{3}$. A CEM II B-L $32.5 \mathrm{~N}$ cement with density of $3030 \mathrm{~kg} / \mathrm{m}^{3}$ was also used.

The used PCM are composed of a wall in melamine-formaldehyde and a core in paraffin with temperature transition of about $22.5^{\circ} \mathrm{C}$ and enthalpy of $147.9 \mathrm{~kJ} / \mathrm{kg}$. This exhibits a transition temperature of $24{ }^{\circ} \mathrm{C}$ in the heating cycle and $21{ }^{\circ} \mathrm{C}$ in the cooling cycle. In order to determine the 
dimensions of PCM microcapsules, granulometry tests were performed using a laser particle size analyzer. It was possible to observe a particle size distribution between 5.8 to $339 \mu \mathrm{m}$ and an average particle size of $43.91 \mu \mathrm{m}$ (Fig. 1).

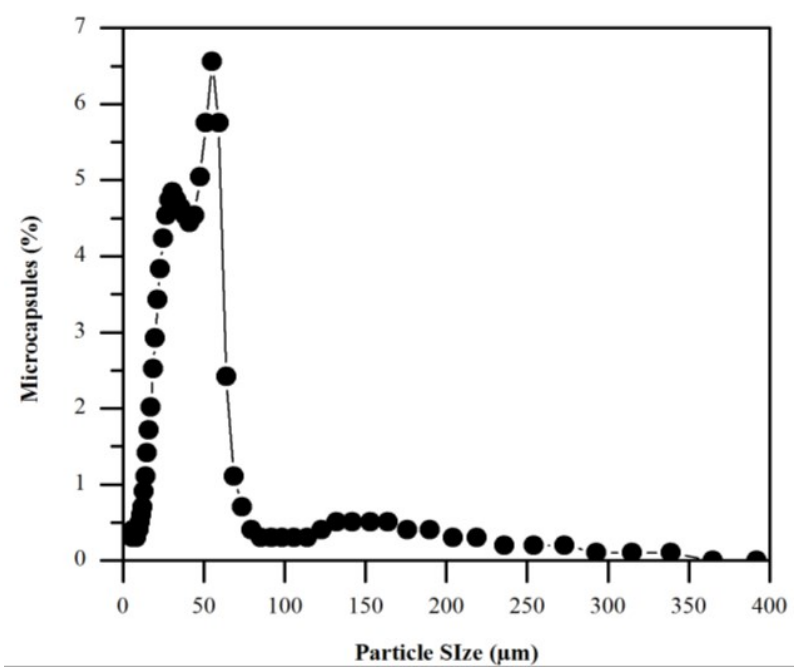

Fig. 1. Particle size of PCM microcapsules.

The superplasticizer used was a polyacrylate, with a density of $1050 \mathrm{~kg} / \mathrm{m}^{3}$. The sand used has an average particle size of $439,9 \mu \mathrm{m}$ and a density of $2600 \mathrm{~kg} / \mathrm{m}^{3}$. Finally, the used fibers are synthetic fibers of polyamide, with a length of $6 \mathrm{~mm}$ and a density of $1380 \mathrm{~kg} / \mathrm{m}^{3}$.

Compositions and fabrication. In order to develop this study an experimental campaign was considered, with the main goal of evaluating the durability of mortars doped with PCM. Twelve compositions were developed and evaluated when submitted to extreme environmental conditions.

The PCM content was fixed in $0 \%$ and $40 \%$ of mass of aggregate. In order to overcome some of the problems related with the shrinkage and consequent cracking, polyamide fibers and superplasticizer were incorporated.

The mixture procedure and specimens preparation for the water absorption by capillarity tests and water absorption by immersion tests were performed in accordance to the standard EN 1015-11 [11]. For the freeze-thaw tests 5 cubic specimens with $50 \times 50 \times 50 \mathrm{~mm}^{3}$ were prepared. After their preparation all the specimens were stored during 7 days in polyethylene bags and subsequently placed in the laboratory at regular room temperature (about $22^{\circ} \mathrm{C}$ ) during 21 days.

The studied compositions are presented in Table 1. The used compositions have different contents of PCM and different binders. In order to overcome some of the problems related with the low flexural and compressive strength verify in the aerial lime based mortars with incorporation of microcapsules of PCM, it was decided to incorporate a higher content of binder.

\section{Test results and discussion}

Water absorption by capillarity. The water absorption by capillarity tests were performed based on the European standard EN 1015-18 [12]. The samples were obtained by cutting the prismatic specimens with dimensions of $40 \times 40 \times 160 \mathrm{~mm}^{3}$, previously subjected to flexural tests. For each composition 3 specimens were prepared, resulting in 6 samples after flexural tests.

For each specimen it was decided to put the failure surface resulting from the flexural test in contact with the water. Thus, it was possible to ensure that the porosity present in the surface in contact with the water was close to the real porosity present in the studied mortars. This removes the possibility of analysing one surface with higher content of material of small dimensions, which would affect the results of these tests.

The quantification of absorbed water was performed by conducting successive weightings in specimens. These weight measurements were made according to a previously established weighting 
plan, beginning with the first contact of the specimens with water (Table 2). In order to evaluate the progress of water absorption until the weight stabilization, periodic measurements were performed during 9 days.

Table 1. Mortars formulation $\left(\mathrm{kg} / \mathrm{m}^{3}\right)$.

\begin{tabular}{|c|c|c|c|c|c|c|c|}
\hline Composition & \multicolumn{2}{|c|}{ Binder } & Sand & PCM & SP & Fibers & Water/Binder \\
\hline CA500-0PCM & Aerial Lime & 500 & 1447.2 & 0 & 15 & 0 & 0.45 \\
\hline CA800-40PCM & Aerial Lime & 800 & 451.2 & 180.5 & 24 & 0 & 0.34 \\
\hline CA800-40PCM-F & Aerial Lime & 800 & 425.2 & 170.1 & 24 & 8 & 0.36 \\
\hline CH500-0PCM & Hydraulic lime & 500 & 1351.1 & 0 & 15 & 0 & 0.54 \\
\hline CH500-40PCM & Hydraulic lime & 500 & 571.6 & 228.6 & 15 & 0 & 0.62 \\
\hline CH500-40PCM-F & Hydraulic lime & 500 & 567.2 & 226.9 & 15 & 5 & 0.62 \\
\hline C32.5N500-0PCM & CEM II B-L 32.5N & 500 & 1418.8 & 0 & 15 & 0 & 0.55 \\
\hline C32.5N500-40PCM & CEM II B-L 32.5N & 500 & 644.3 & 257.7 & 15 & 0 & 0.56 \\
\hline C32.5N500-40PCM-F & CEM II B-L 32.5N & 500 & 622.2 & 248.8 & 15 & 5 & 0.59 \\
\hline G500-0PCM & Gypsum & 500 & 1360.4 & 0 & 15 & 0 & 0.56 \\
\hline G500-40PCM & Gypsum & 500 & 540.1 & 216.0 & 15 & 0 & 0.70 \\
\hline G500-40PCM-F & Gypsum & 500 & 535.8 & 214.3 & 15 & 5 & 0.70 \\
\hline
\end{tabular}

The obtained results allowed us to determine the water absorption by capillary of the different mortars. The capillary absorption coefficient was determined according to Eq. 1.

$$
\mathrm{C}=\left(\mathrm{M}_{2}-\mathrm{M}_{1}\right) /\left(\left(\mathrm{t}_{\mathrm{f}}-\mathrm{t}_{\mathrm{i}}\right)^{0.5}\right) \text {. }
$$

Where:

C - Capillary absorption coefficient $\left(\mathrm{kg} /\left(\mathrm{m}^{2} \cdot \mathrm{min}^{0.5}\right)\right.$;

$\mathrm{M}_{1}$ - Weight of the specimen in contact with water at the instant 10 minutes $\left(\mathrm{kg} / \mathrm{m}^{2}\right)$;

$\mathrm{M}_{2}$ - Weight of the specimen in contact with water at the instant 90 minutes $\left(\mathrm{kg} / \mathrm{m}^{2}\right)$;

$\mathrm{t}_{\mathrm{f}}-$ Final time, instant 90 minutes $(\mathrm{min})$;

$\mathrm{t}_{\mathrm{i}}$ - Initial time, instant 10 minutes (min).

Table 2. Planning of the measurements of the water absorption by capillarity tests in the first day.

\begin{tabular}{|c|c|c|}
\hline Measurement & Instant (h) & $\begin{array}{c}\text { Instant } \\
{[\mathrm{min}]}\end{array}$ \\
\hline 1 & 0 & 0 \\
\hline 2 & 0.17 & 10 \\
\hline 3 & 0.5 & 30 \\
\hline 4 & 1 & 60 \\
\hline 5 & 1.5 & 90 \\
\hline 6 & 2 & 120 \\
\hline 7 & 3 & 180 \\
\hline 8 & 4 & 240 \\
\hline 9 & 5 & 300 \\
\hline 10 & 6 & 360 \\
\hline 11 & 24 & 1440 \\
\hline
\end{tabular}

According to Fig. 2 and Table 3 it was possible to verify that the gypsum based mortars present the higher coefficient of water absorption by capillarity. Simultaneously, the cement based mortars show the lower coefficient of water absorption by capillarity compared with the mortars based on the other binders.

The incorporation of $40 \%$ of PCM caused a decrease in the capillary absorption coefficient of $15 \%$ in hydraulic lime based mortars and $33 \%$ in the cement based mortars. On the other hand, it 
was also possible to observe an increase in capillary absorption coefficient of $9 \%$ for aerial lime based mortars and $17 \%$ for gypsum based mortars.

The incorporation of $1 \%$ of polyamide fibers had the main objective of control the shrinkage in the developed mortars. Their presence in mortars caused a decrease in the capillary absorption coefficient of about $4 \%$ in the aerial lime based mortars, $13 \%$ in the gypsum based mortars and $63 \%$ in the cement based mortars. The hydraulic lime based mortars did not present any change in the capillary absorption coefficient with the incorporation of fibers. This situation can be explained by the ability of fibers to reduce porosity of the mortars, reducing the effect of the presence of a higher ratio water/binder.

Fig. 3 shows the behavior of the studied mortars during the 9 days of testing. According with the results of the coefficient of water absorption by capillarity, it was possible to observe once again that the gypsum based mortars have a faster saturation process, presenting all specimens statured after 150 minutes in contact with water. The cement based mortars showed a slower velocity of saturation, tending to stabilize after 7 days of testing.

In order to evaluate the influence of the presence of PCM and fibers in the water absorption coefficient classification, the mortars were classified according to standard NP EN 998-1 (Table 4) [13]. It was verified that the incorporation of PCM and fibers did not cause any variation in the classification of mortars.

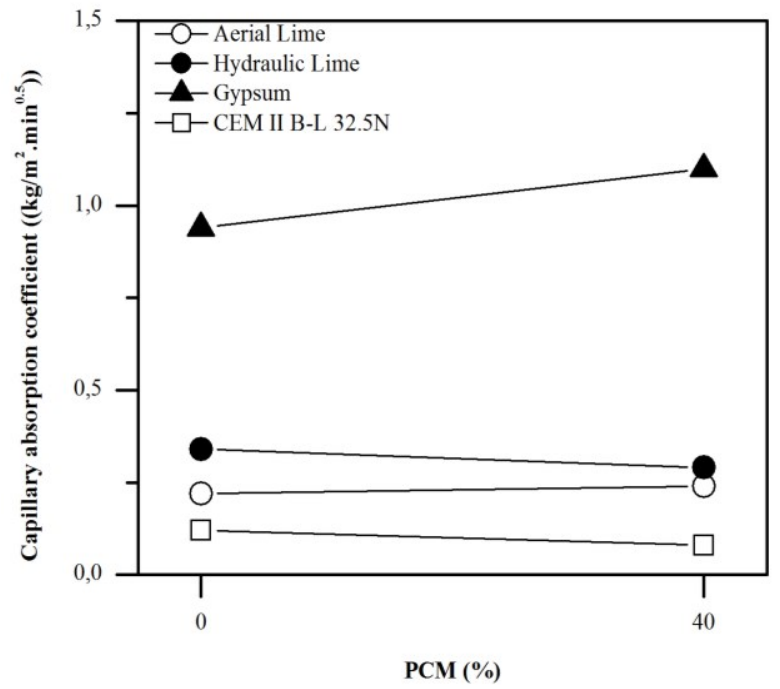

a)

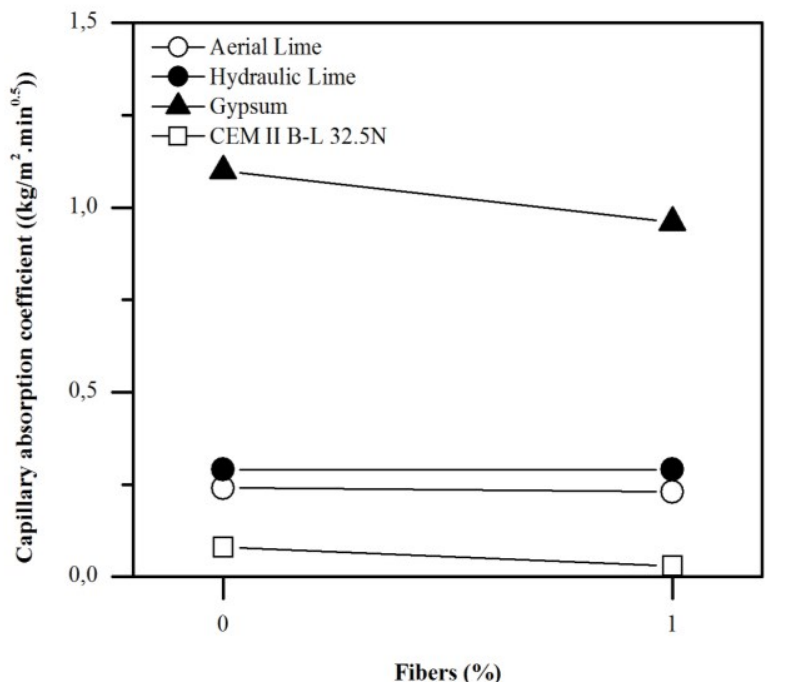

b)

Fig. 2. Capillary absorption coefficient: a) Variation with PCM content, b) Variation with fibers content.

Water absorption by immersion. The water absorption by immersion tests were based in the specification LNEC E 394 [14]. The samples were obtained by cutting the prismatic specimens with dimensions of $40 \times 40 \times 160 \mathrm{~mm}^{3}$, previously subjected to flexural tests. For each composition, 3 specimens were prepared, resulting in 6 samples after flexural tests.

Initially the specimens were dried in oven until constant mass. Subsequently, they were saturated with water at a temperature of $20 \pm 3^{\circ} \mathrm{C}$. Finally, after saturation it was determined the hydrostatic mass.

Table 3. Capillary absorption coefficient $\left(\mathrm{kg} /\left(\mathrm{m}^{2} \cdot \mathrm{min}^{0.5}\right)\right.$.

\begin{tabular}{|c|c|c|}
\hline Composition & Binder & $\begin{array}{c}\text { Capillary absorption } \\
\text { coefficient }\left[\mathrm{kg} /\left(\mathrm{m}^{2} \cdot \min ^{0.5}\right]\right.\end{array}$ \\
\hline CA500-0PCM & Aerial Lime & 0.22 \\
\hline CA800-40PCM & Aerial Lime & 0.24 \\
\hline CA800-40PCM-F & Aerial Lime & 0.23 \\
\hline
\end{tabular}




\begin{tabular}{|c|c|c|}
\hline CH500-0PCM & Hydraulic lime & 0.34 \\
\hline CH500-40PCM & Hydraulic lime & 0.29 \\
\hline CH500-40PCM-F & Hydraulic lime & 0.28 \\
\hline C32.5N500-0PCM & CEM II B-L 32.5N & 0.12 \\
\hline C32.5N500-40PCM & CEM II B-L 32.5N & 0.08 \\
\hline C32.5N500-40PCM-F & CEM II B-L 32.5N & 0.03 \\
\hline G500-0PCM & Gypsum & 0.94 \\
\hline G500-40PCM & Gypsum & 1.10 \\
\hline G500-40PCM-F & Gypsum & 0.96 \\
\hline
\end{tabular}
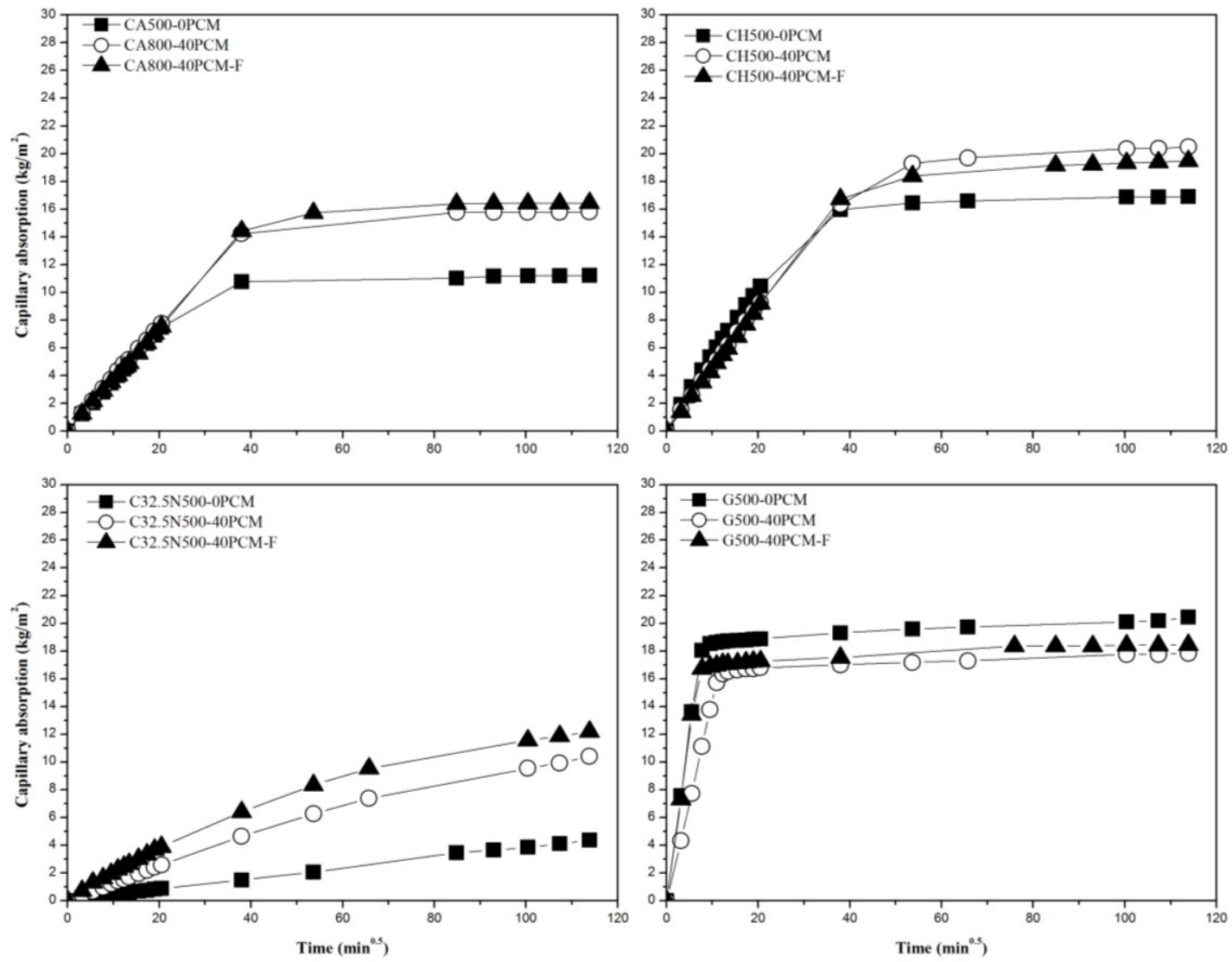

Fig. 3. Water absorption by capillarity.

The obtained results allowed us to determine the water absorption by immersion of the different mortars. This was determined according to the Eq. 2.

$$
\mathrm{W}=\left(\mathrm{M}_{1}-\mathrm{M}_{3}\right) /\left(\mathrm{M}_{1}-\mathrm{M}_{2}\right) \times 100
$$

Where:

W - Water absorption by immersion (\%);

$\mathrm{M}_{1}$ - Mass of saturated specimen (g);

$\mathrm{M}_{2}$ - Hydrostatic mass of saturated specimen ( $\left.\mathrm{g}\right)$;

$\mathrm{M}_{3}$ - Mass of dried specimen $(\mathrm{g})$.

Regarding Fig. 4, it was possible to observe that the incorporation of $40 \%$ of PCM microcapsules in mortars caused an increase in water absorption greater than $14 \%$. However, the incorporation of $1 \%$ polyamide fibers resulted in a decrease of water absorption greater than $8 \%$, with the exception of hydraulic lime based mortars, which value did not suffer any change. It was also possible to identify that the gypsum based mortars and hydraulic lime based mortars presented the higher water absorption values. On the other hand, the cement based mortars showed a lower water absorption. 
Table 4. Classification of mortars according to standard NP EN 998-1:2010.

\begin{tabular}{|c|c|c|}
\hline Composition & Binder & Classification NP EN 998-1:2010 \\
\hline CA500-0PCM & Aerial Lime & W1 \\
\hline CA800-40PCM & Aerial Lime & W1 \\
\hline CA800-40PCM-F & Aerial Lime & W1 \\
\hline CH500-0PCM & Hydraulic lime & W1 \\
\hline CH500-40PCM & Hydraulic lime & W1 \\
\hline CH500-40PCM-F & Hydraulic lime & W2 \\
\hline C32.5N500-0PCM & CEM II B-L 32.5N & W2 \\
\hline C32.5N500-40PCM & CEM II B-L 32.5N & W2 \\
\hline C32.5N500-40PCM-F & CEM II B-L 32.5N & W0 \\
\hline G500-0PCM & Gypsum & W0 \\
\hline G500-40PCM & Gypsum & W0 \\
\hline G500-40PCM-F & Gypsum & \\
\hline
\end{tabular}
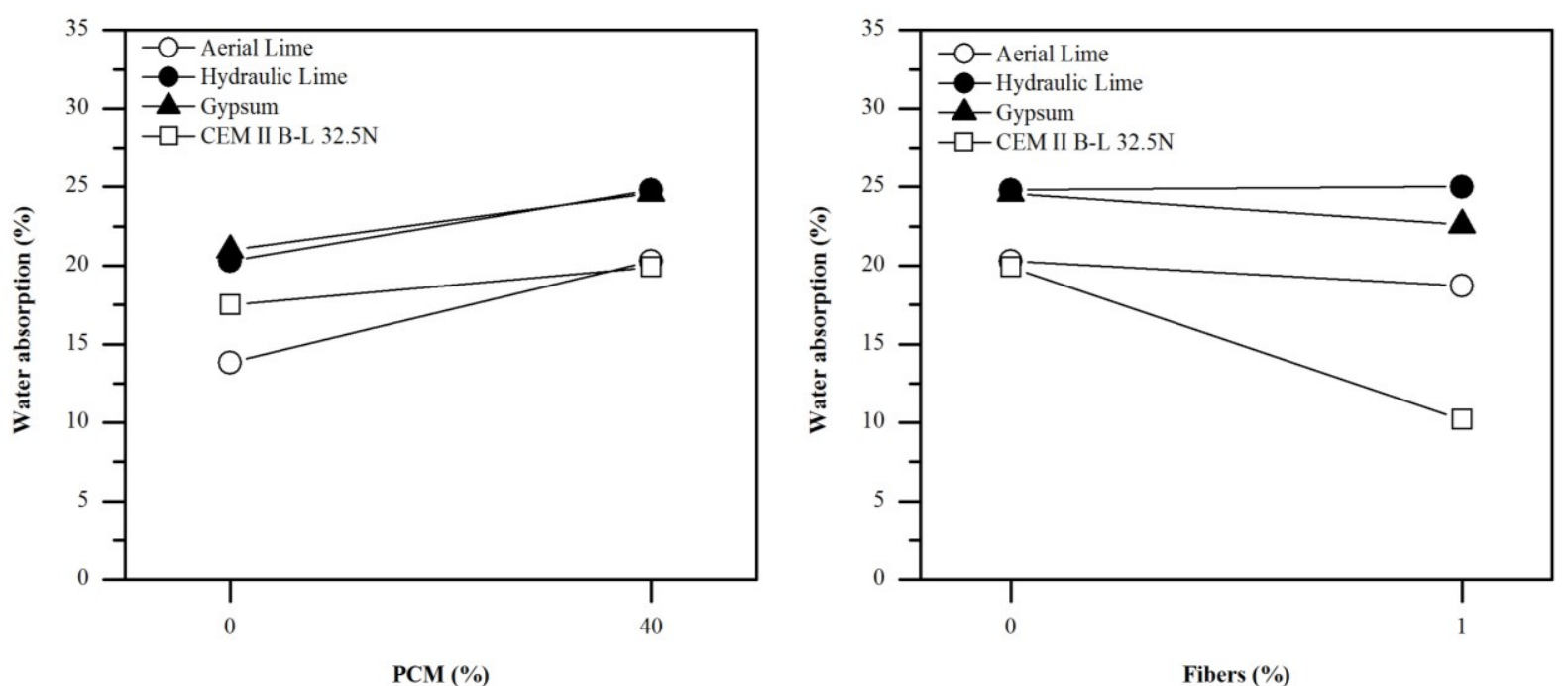

Fig. 4. Water absorption of the mortars.

Freeze-thaw resistance. The durability of mortar to freeze-thaw cycles is related to their ability to absorb water, the speed of water absorption, the presence of porous structure and the resistant capacity to volume variations when the water changes to the liquid state to a solid state. Thus, cyclic freeze-thaw test have an important and decisive role in the durability of mortars.

These tests consist of submitting the specimens to cycles of positive and negative temperatures. Note that when there are negative temperatures, the water inside the structure of the mortars freezes and consequently increases its volume. If the pores of the mortar are not saturated, the problems that can arise maybe minimal, since the volume of frozen water is inferior to the volume of the pores. However, if the pores are saturated, the resulting increase in volume of freezing gives rise to pressure on the microstructure of mortars, which can cause cracking and even the partial destruction of the specimens.

The freeze-thaw tests were determined based in the standard CEN/TS 12390-9 [15]. The equipment used for the tests was programmed with a law temperature and humidity. Each freezethaw cycle has duration of 24 hours (Fig. 5) and a total of 56 cycles were performed. During each cycle of freeze-thaw, temperature ranges between to the maximum of $24^{\circ} \mathrm{C}$ and the minimum of -18 ${ }^{\circ} \mathrm{C}$.

Initially the specimens were saturated and then submitted to the temperature cycles. During the test the specimen was placed in contact with water. This was carried out with the purpose of reabsorbing the water lost by evaporation and also by the action of the ventilation of the equipment itself. Thus it was possible to ensure the constant saturation of the specimens. The equipment was also programmed with a constant relative humidity of $90 \%$, in order to avoid large losses in mass by 
evaporation of water. In order to account the variation of mass, each sample was individually placed in a container able to contain its mass losses resulting from degradation suffered during the freezethaw cycles (Fig. 6). The quantification of mass losses was performed by conducting successive weightings of the specimens. These weight measurements were made according to a previously established plan of weighting, beginning in the first cycle (Table 5).

According to Fig. 11, it was possible to observe the behaviour of the mortars during the freezethaw cycles. The mortars showed different behaviours when subjected to freeze-thaw cycles. In general, it can be concluded that the cement-based mortars are those that exhibit a higher resistance to freeze-thaw action, since that does not present a significant mass loss. On the other hand, the more sensitive mortars are the aerial lime based mortars, which show a total loss of the specimens in few cycles.

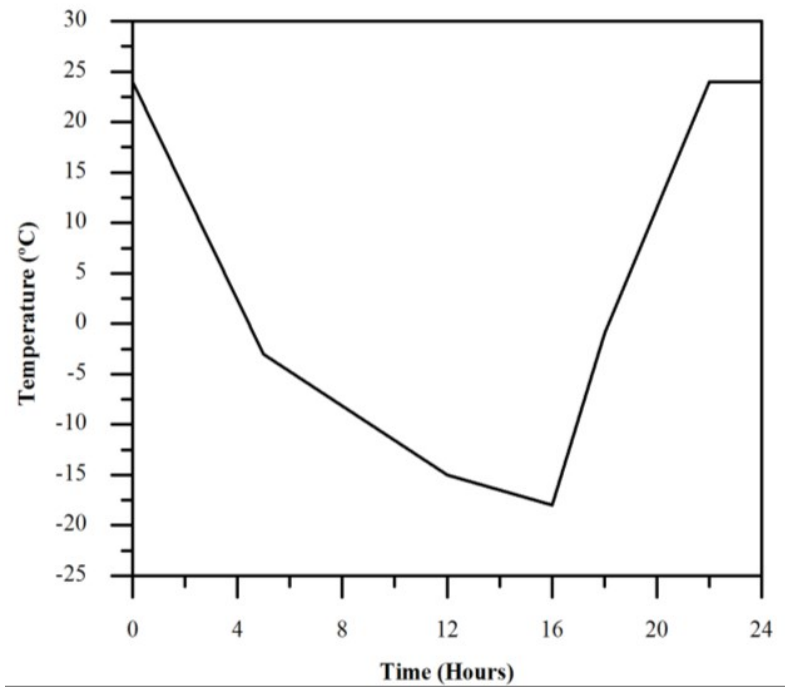

Fig. 5. Freeze-thaw cycle.

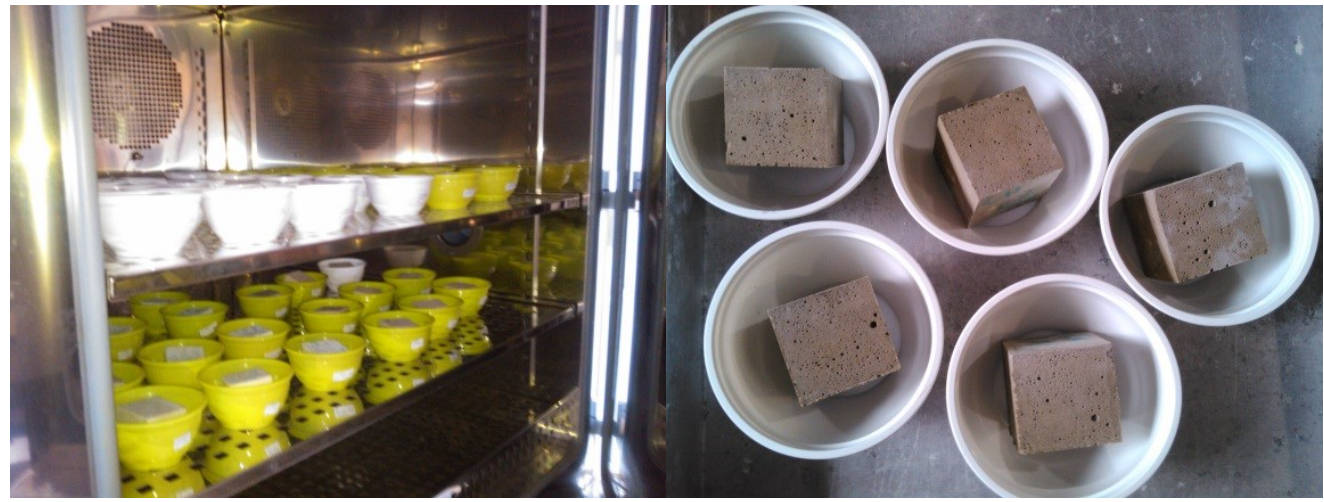

Fig. 6. Specimens in the test equipment.

Table 5. Planning of the measurements of freeze-thaw tests.

\begin{tabular}{|c|c|c|}
\hline Measurement & Cycle & Instant $[\mathrm{h}]$ \\
\hline 1 & 0 & 0 \\
\hline 2 & 1 & 24 \\
\hline 3 & 2 & 48 \\
\hline 4 & 3 & 72 \\
\hline 5 & 6 & 144 \\
\hline 6 & 8 & 192 \\
\hline 7 & 13 & 312 \\
\hline 8 & 20 & 480 \\
\hline 9 & 27 & 648 \\
\hline 10 & 41 & 984 \\
\hline 11 & 56 & 1344 \\
\hline
\end{tabular}


Fig. 7 to Fig. 10 show the specimens of the different compositions before starting the freeze-thaw tests (cycle 0$)$.

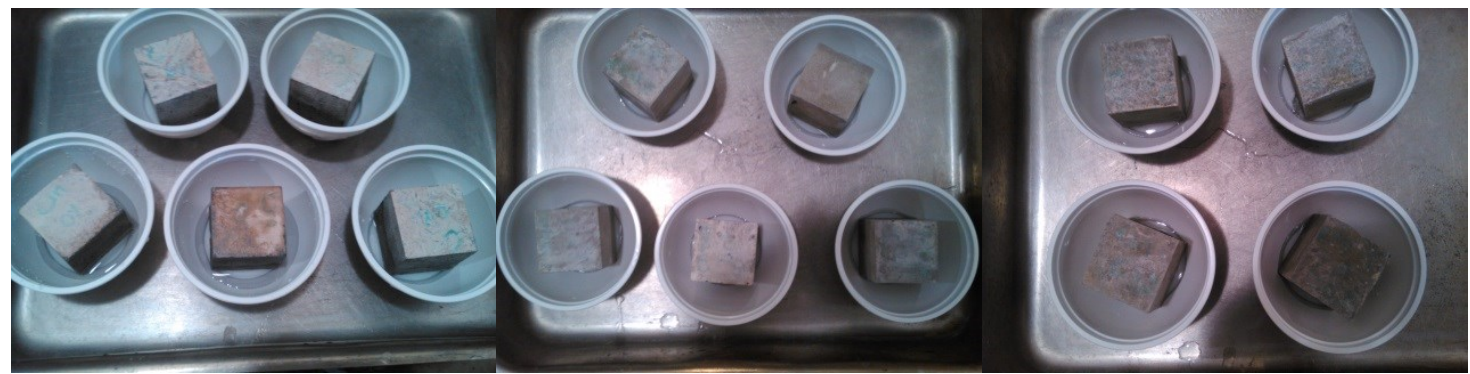

Fig. 7. Specimens of the cement based mortars in cycle 0: C32.5N500-0PCM, C32.5N50040PCM and C32.5N500-F-40PCM, from the left to right.

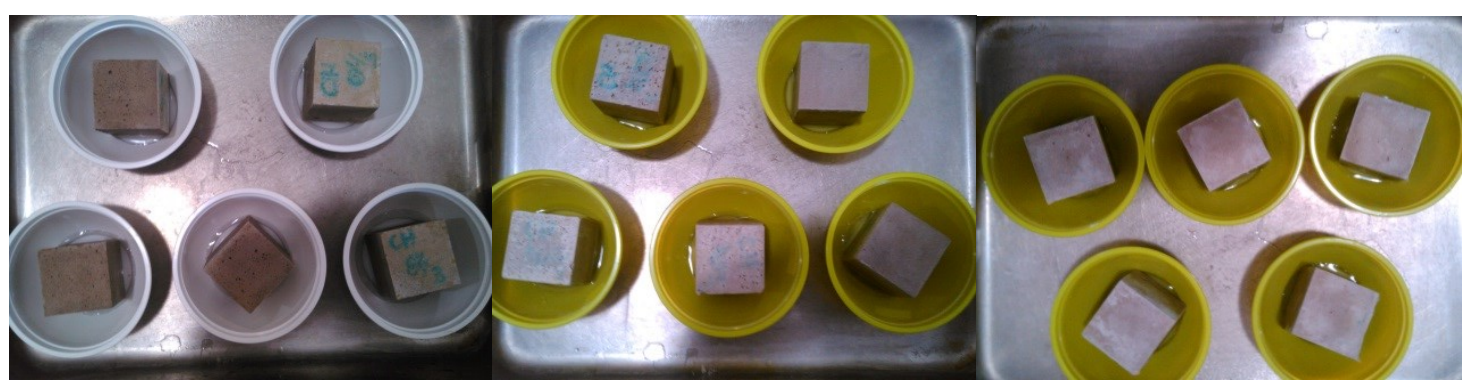

Fig. 8. Specimens of the hydraulic lime based mortars in cycle 0: CH500-0PCM, CH500-40PCM e CH500-40PCM-F, from the left to right.

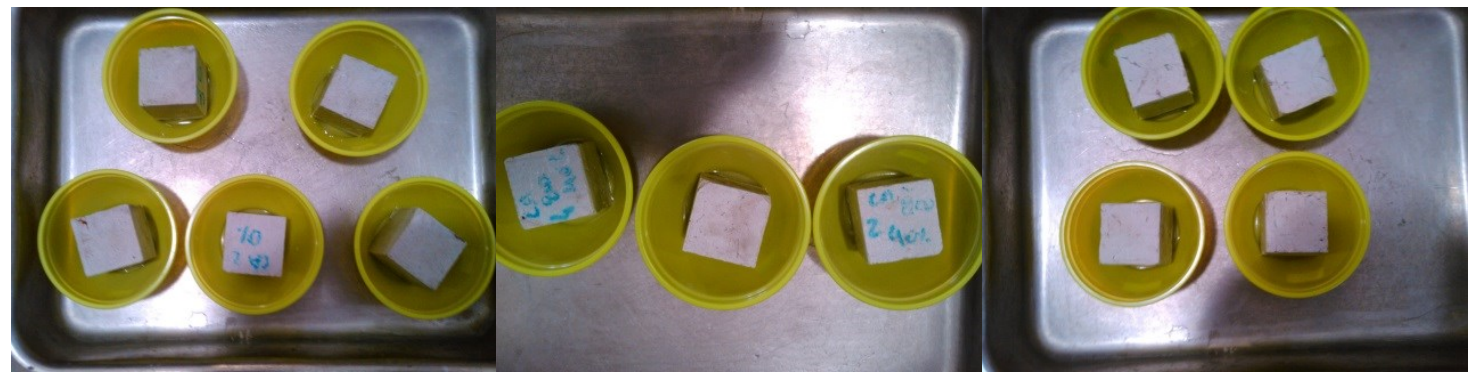

Fig. 9. Specimens of the aerial lime based mortars in cycle 0: CA500-0PCM, CA800-40PCM e CA800-40PCM-F, from the left to right.

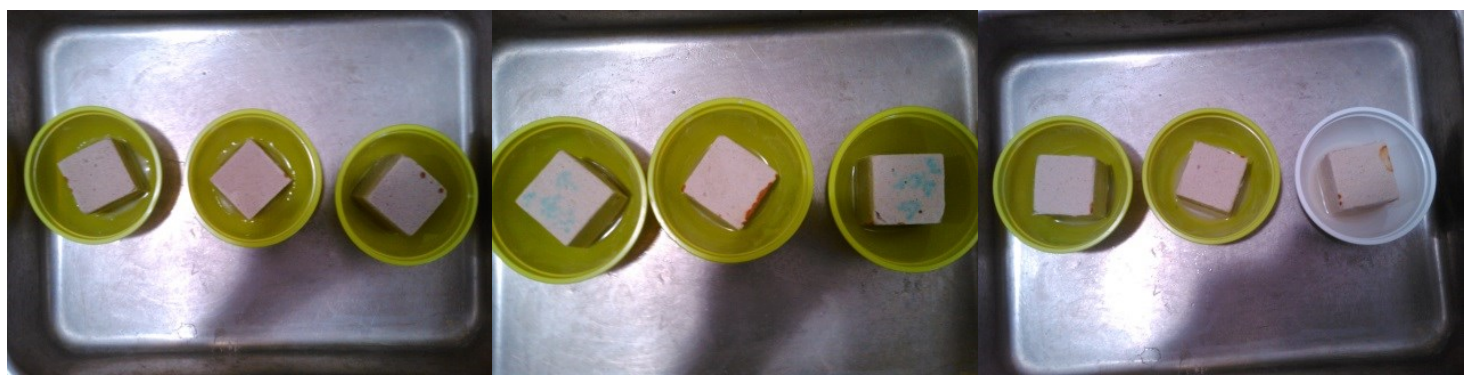

Fig. 10. Specimens of the gypsum based mortars in cycle 0: G500-0PCM, G500-40PCM e G50040PCM-F, from the left to right. 

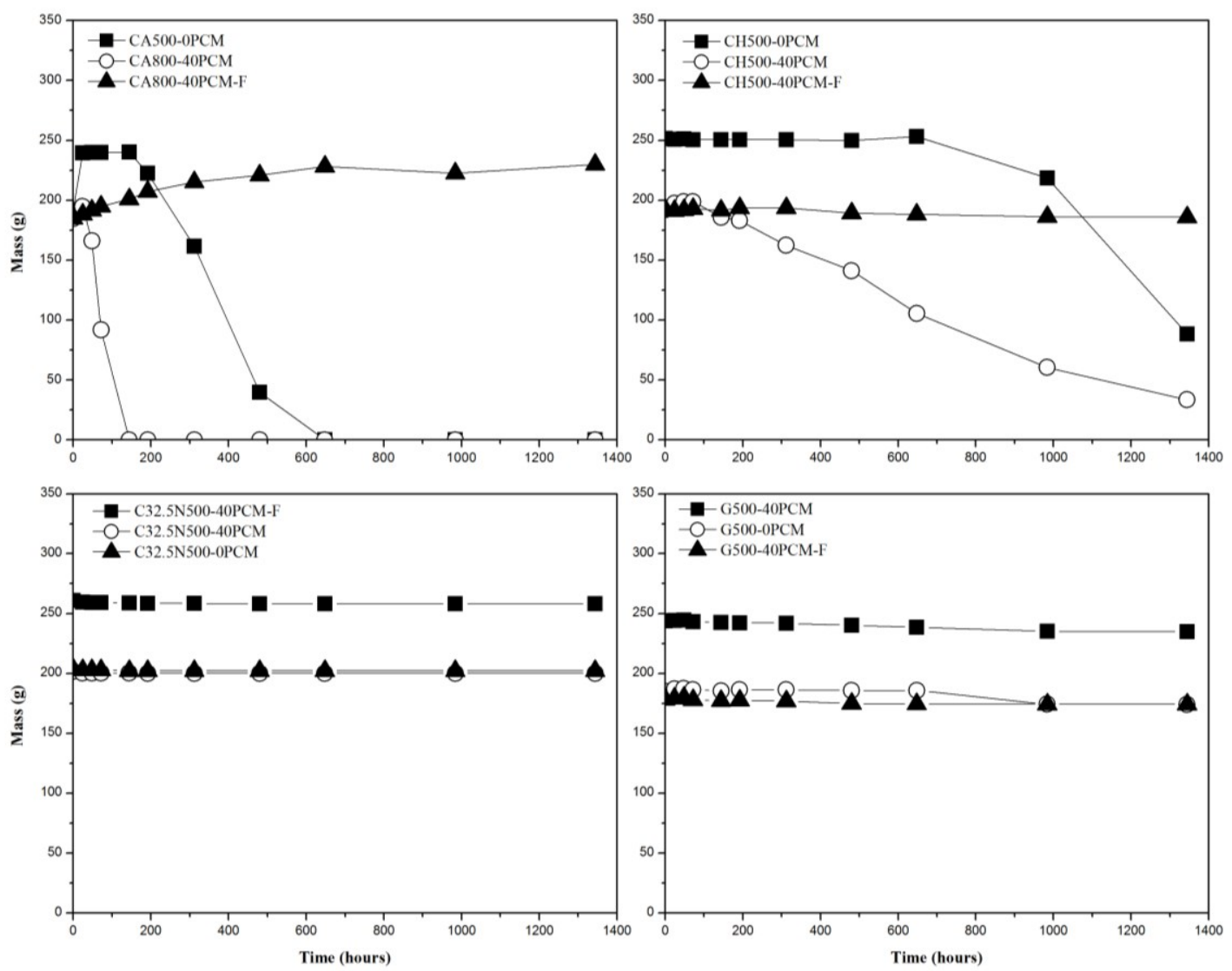

Fig. 11. Behaviour of the mortars to freeze-thaw cycles.

Table 6 shows the total degradation suffered by the specimens of the different compositions tested. It was observed that the incorporation of PCM generally resulted in higher losses of the material during the freeze-thaw action, demonstrating in this way that the incorporation of PCM microcapsules in mortars becomes them more susceptible to be attacked. This behaviour is related with the ease that the aggressive agents have to penetrate into the mortar and can be evidenced by the increase in porosity with the incorporation of PCM. Moreover, the incorporation of fibers in all tested mortars allowed to observe a decrease in mass loss, associated with a higher resistance to the passage of the aggressive agents, which once again is confirmed by the decrease of porosity present in mortar caused by the introduction of polyamide fibers.

Fig. 12 to Fig. 15 show the final aspect of the specimens for the different compositions tested.

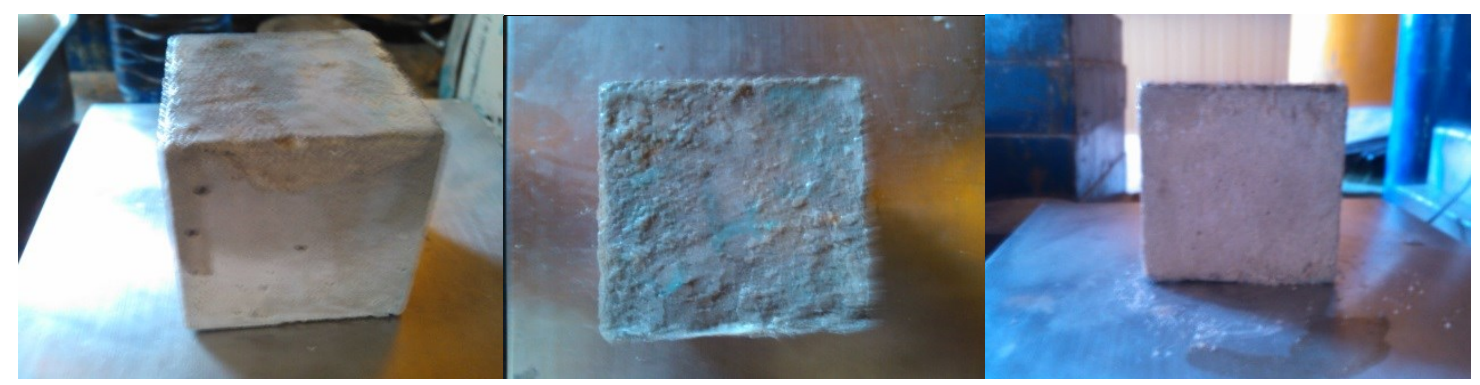

Fig. 12. Final aspect of the specimens of the cement based mortars in the cycle 56: C32.5N500OPCM, C32.5N500-40PCM and C32.5N500-F-40PCM, from the left to right. 
Table 6. Mass losses in the freeze-thaw tests.

\begin{tabular}{|c|c|c|}
\hline Composition & Binder & Mass losses [\%] \\
\hline CA500-0PCM & Aerial Lime & 100 \\
\hline CA800-40PCM & Aerial Lime & 100 \\
\hline CA800-40PCM-F & Aerial Lime & 24.3 \\
\hline CH500-0PCM & Hydraulic lime & 64.9 \\
\hline CH500-40PCM & Hydraulic lime & 82.6 \\
\hline CH500-40PCM-F & Hydraulic lime & 3.4 \\
\hline C32.5N500-0PCM & CEM II B-L 32.5N & 1.1 \\
\hline C32.5N500-40PCM & CEM II B-L 32.5N & 0.7 \\
\hline C32.5N500-40PCM-F & CEM II B-L 32.5N & 0.6 \\
\hline G500-0PCM & Gypsum & 3.6 \\
\hline G500-40PCM & Gypsum & 5.9 \\
\hline G500-40PCM-F & Gypsum & 2.1 \\
\hline
\end{tabular}

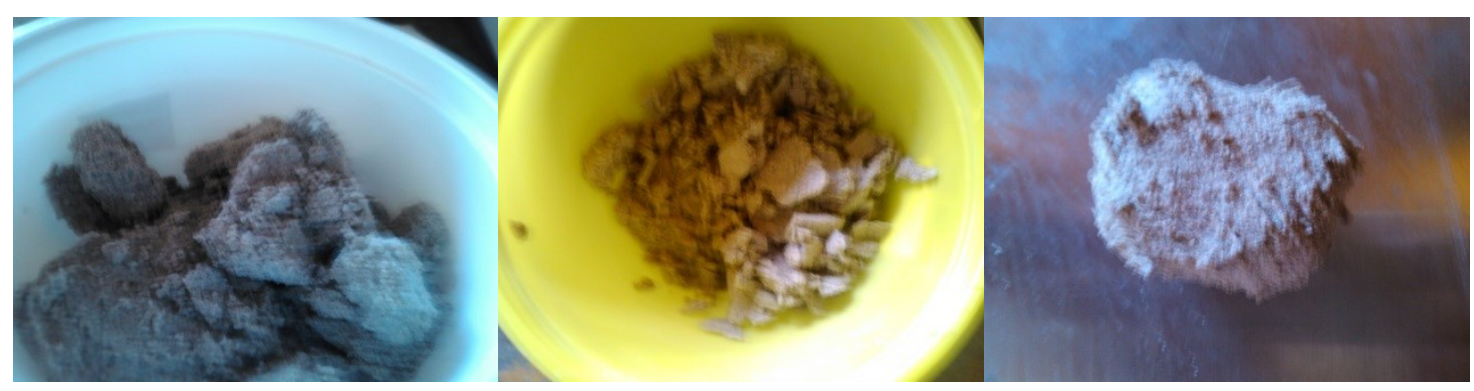

Fig. 13. Final aspect of the specimens of the hydraulic lime based mortars in the cycle 56 : CH500-0PCM, CH500-40PCM e CH500-40PCM-F, from the left to right.

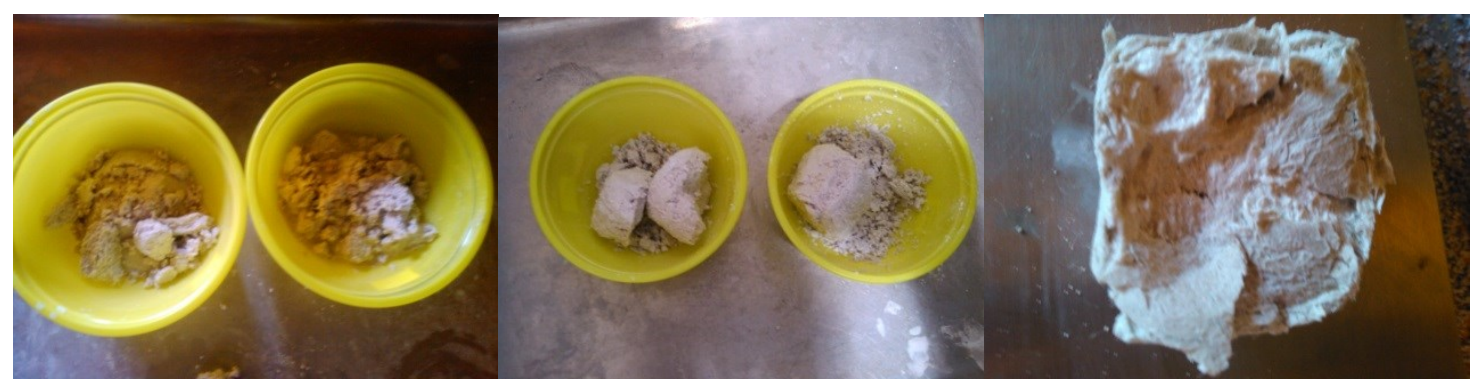

Fig. 14. Final aspect of the specimens of the aerial lime based mortars: CA500-0PCM in the cycle $27, \mathrm{CA} 800-40 \mathrm{PCM}$ in the cycle 6 e CA800-40PCM-F I the cycle 56 , from the left to right.

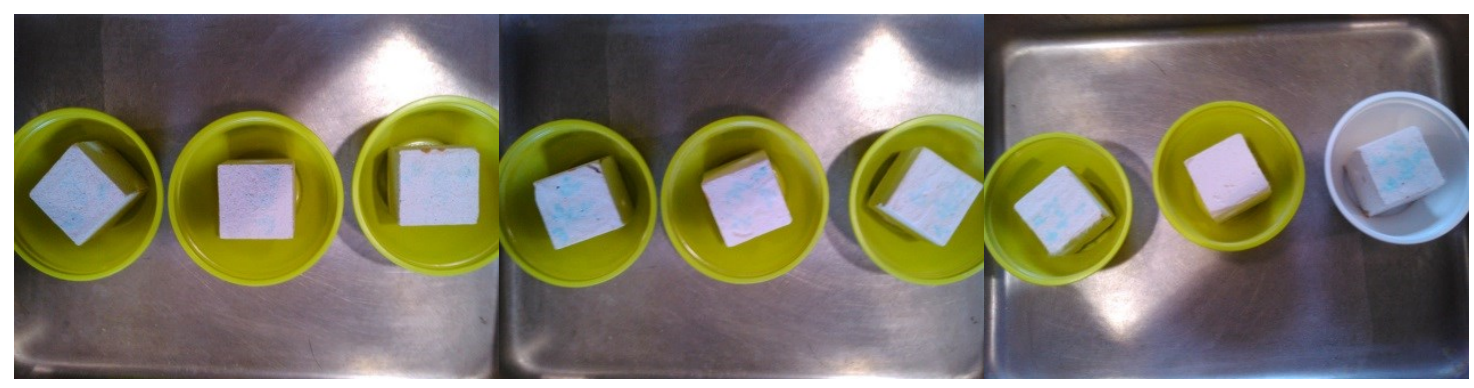

Fig. 15. Final aspect of the specimens of the gypsum based mortars in the cycle 56: G500-0PCM, G500-40PCM e G500-40PCM-F, from the left to right. 


\section{Conclusion}

Based on these results, it can be concluded that the incorporation of phase change material in mortars affects the durability of the mortars developed. Based on the tests of water absorption by immersion it was observed that the incorporation of $40 \%$ of PCM causes an increase in the porosity of the mortars. This increase also resulted in higher sensitivity of the freeze-thaw test. However, this ease of penetration of aggressive agents may be decreased by incorporation of $1 \%$ of polyamide fibers.

Thus, it can be concluded that the cement based mortars are the ones that have a lower sensitivity to freeze-thaw actions and lower porosity, consequently presenting a better performance. Moreover, aerial lime based mortars showed a higher deterioration in the freeze-thaw test, presenting a sensitive behaviour to aggressive agents.

\section{References}

[1] A. Azevedo, Betões de elevado desempenho com incorporação de cinzas volantes, PhD Thesis, Department of Civil Engineering, University of Minho (2002).

[2] A. Izaguirre, J. Lanas, J. Álvarez, Ageing of lime mortars with admixtures: Durability and strength assessment, Cement and Concrete Research. 40 (2010) 1081-1095.

[3] Y. Zhang, G. Zhou, K. Lin, K. Zhang, H. Di, Application of latent heat thermal energy storage in buildings: State-of-the-art and outlook, Build Environ. 42 (2007) 2197-2209.

[4] B. Zalba, J. Marín, L. Cabeza, H. Mehling, Review on thermal energy storage with phase change: materials, heat transfer analysis and applications, Appl Therm Eng. 23 (2003) 251-283.

[5] L. Cabeza, A. Castell, C. Barreneche, A. Gracia, A. Fernández, Materials used as PCM in thermal energy storage in buildings: A review, Renew Sustainable Energy Reviews. 15 (2011) 1675-1695.

[6] V. Tyagi, S. Kaushik, S.Tyagi, T.Akiyama, Development of phase change materials based microencapsulated technology for buildings: A review, Renew Sustainable Energy Reviews. 15 (2011) 1373-1391.

[7] A. Sharma, V. Tyagi, C. Chen, D. Buddhi, Review on thermal energy storage with phase change materials and applications, Renew Sustainable Energy Reviews. 13 (2009) 318-345.

[8] S. Cunha, V. Alves, J. B. Aguiar, V. M. Ferreira, Use of phase change materials microcapsules in aerial lime and gypsum mortars, Cement Wapno Beton. Special Issue (2012) 17-21.

[9] S. Cunha, J. B. Aguiar, M. Kheradmend, L. Bragança, V. M. Ferreira, Thermal mortars with incorporation of PCM microcapsules, Restoration of Buildings and Monuments. 19 (2013) 171-177.

[10] S. Cunha, J. B. Aguiar, V. M. Ferreira, A. Tadeu, Influence of adding encapsulated phase change materials in aerial lime based mortars, Advanced Materials Research. 687 (2013) 255-261.

[11] European Committee for Standardization (CEN). EN 1015-11:1999. Methods of test for mortar for masonry - Part 11: Determination of flexural and compressive strength of hardened mortar (1999).

[12] European Committee for Standardization (CEN). EN 1015-18:2002. Methods of test for mortar for masonry - Part 18: Determination of water absorption coefficient due to capillary action of hardened mortar (2002). 
[13] Portuguese Institute for Quality (IPQ). NP EN 998-1:2013. Specification for masonry mortars Part 1: Plastering mortars for interior and exterior (2013) (in Portuguese).

[14] National Laboratory of Civil Engineering (LNEC). Specification E 394, ConcreteDetermination of water absorption by immersion (1993) (in Portuguese).

[15] European Committee for Standardization (CEN). CEN/TS 12390-9:2006. Testing hardened concrete - Part 9: Freeze-thaw resistance (2006). 


\section{Sustainable Construction Materials}

10.4028/www.scientific.net/KEM.634

\section{Mortars with Phase Change Materials - Part II: Durability Evaluation}

10.4028/www.scientific.net/KEM.634.33

\section{DOI References}

[2] A. Izaguirre, J. Lanas, J. Álvarez, Ageing of lime mortars with admixtures: Durability and strength assessment, Cement and Concrete Research. 40 (2010) 1081-1095.

http://dx.doi.org/10.1016/j.cemconres.2010.02.013

[3] Y. Zhang, G. Zhou, K. Lin, K. Zhang, H. Di, Application of latent heat thermal energy storage in buildings: State-of-the-art and outlook, Build Environ. 42 (2007) 2197-2209.

http://dx.doi.org/10.1016/j.buildenv.2006.07.023

[5] L. Cabeza, A. Castell, C. Barreneche, A. Gracia, A. Fernández, Materials used as PCM in thermal energy storage in buildings: A review, Renew Sustainable Energy Reviews. 15 (2011) 1675-1695. http://dx.doi.org/10.1016/j.rser.2010.11.018

[6] V. Tyagi, S. Kaushik, S. Tyagi, T. Akiyama, Development of phase change materials based microencapsulated technology for buildings: A review, Renew Sustainable Energy Reviews. 15 (2011) 13731391.

http://dx.doi.org/10.1016/j.rser.2010.10.006

[7] A. Sharma, V. Tyagi, C. Chen, D. Buddhi, Review on thermal energy storage with phase change materials and applications, Renew Sustainable Energy Reviews. 13 (2009) 318-345.

http://dx.doi.org/10.1016/j.rser.2007.10.005

[9] S. Cunha, J. B. Aguiar, M. Kheradmend, L. Bragança, V. M. Ferreira, Thermal mortars with incorporation of PCM microcapsules, Restoration of Buildings and Monuments. 19 (2013) 171-177.

http://dx.doi.org/10.1515/rbm-2013-6592

[10] S. Cunha, J. B. Aguiar, V. M. Ferreira, A. Tadeu, Influence of adding encapsulated phase change materials in aerial lime based mortars, Advanced Materials Research. 687 (2013) 255-261.

http://dx.doi.org/10.4028/www.scientific.net/AMR.687.255 